\title{
Multifractal analysis of soil fauna diversity indexes
}

\author{
Raimunda Alves Silva (iD, Glécio Machado Siqueira* \\ Universidade Federal do Maranhão - Departamento de Geociências - São Luís (MA), Brazil.
}

\begin{abstract}
The objective of this study was to determine the multifractality of diversity indexes of edaphic fauna in areas with natural vegetation and in agricultural systems. Biological sampling was carried out in seven treatments (millet, maize, soybean, eucalyptus, preserved cerrado, disturbed cerrado and pasture), containing 130 pitfall traps, distributed in transects with $3 \mathrm{~m}$ of spacing between sampling points, totaling $390 \mathrm{~m}$. The multifractal analysis was determined based on the moment method, where estimates such as the capacity dimensions, entropy and the correlation of the diversity indexes were calculated. The soybean area had greater Shannon diversity (2.69), however it had smaller abundance of individuals. The partition functions were adjusted with coefficient of determination $>0.90$. The difference between $D_{-10}-D_{10}$, ranged from 0.080 to 1,707 for Pielou equitability in soybean cultivation, for richness in the area under the cultivation of eucalyptus. The singularity spectra expressed graphs with different degrees of heterogeneity for the soil fauna indexes, and the richness expressed the best structure. The area cultivated with soybean had a monofractal tendency, due to the homogeneous distribution of individuals of the edaphic fauna along the transect. The fractal analysis provided the description of patterns of variability that are not detected by classical methods.
\end{abstract}

Key words: ecological modelling; arthropods communities; multifractality; generalized dimension; singularity spectrum.
Received:

May 7, 2019

Accepted:

Oct 10, 2019

Section Editor:

Osvaldo Guedes Filho

${ }^{*}$ Correspondence author: gleciosiqueira@hotmail.com

\section{INTRODUCTION}

The soil fauna is part of a dynamic and heterogeneous system. This group of organisms has intrinsic properties which have temporal and spatial patterns along the landscape, showing horizontal and vertical variability, which are altered by the management of soil in the agroforestry systems. According to Marichal et al. (2014), the soil fauna components and specially the macrofauna have important role in the soil ecosystem and are indicators of services and edaphic functions. In this way, the knowledge of the spatial and temporal patterns of the soil fauna allows to characterize the different habitats, identifying a series of functional aspects of biodiversity, as well as the understanding of ecosystem functioning (Gholami et al. 2017).

The natural dynamic of soil fauna is altered with time in agricultural systems. Silva et al. (2018) found that the abundance and richness of soil organisms are altered depending on the use and the management. Paul et al. (2015) described that conservationist management practices besides improving the physical and chemical quality of the soil, also provided the increment of the soil fauna and other biological attributes. Mueller et al. (2015) reported that knowledge of edaphic fauna in agricultural systems is essential for ecological recognition, in the estimate of their activity and for investigating sustainable management systems. Few studies are devoted to the investigation of soil fauna in agricultural systems, especially those involving ecological, spatial and temporal modeling. Such studies are necessary to understand the dynamic and interactions in agricultural ecosystems, allowing the maintenance of optimum productivity and sustainable development. 
Korboulewsky et al. (2016) described that soil biodiversity has different spatial scales, which are influenced by a set of environmental factors. For Bardgett and van der Putten (2014), the hierarchy of factors influencing the soil fauna is related to intrinsic processes in populations and to disturbances/variations in the environment, which change the variability in spatial and temporal scale. Gholami et al. (2017) reported that the soil macrofauna had variability of scale within a set of samples. Other studies show that such variation depend on the landscape composition (Marichal et al. 2014; Korboulewsky et al. 2016), vegetation composition, diversity of plants (Wardle et al. 2006), and type of litter (Wardle et al. 2006; Silva et al. 2018), as well as on the physical and chemical attributes of soil (Bardgett and van der Putten 2014; Paul et al. 2015; Silva et al. 2018). In this sense, the structure of the scale of soil fauna diversity can be efficiently analyzed by multifractal methods.

Multifractal analysis connects fractal geometry tools and conventional methods of diversity analysis, consisting on a promising method for the understanding of the distribution of soil fauna scales (Yakimov et al. 2018). A fractal system is described by a number of structural elements represented by a power law, which describes the fractal dimension of the object under study (Mandelbrot 1982). A multifractal system comprises intertwined fractal subsets with various dimensions (Yakimov et al. 2018), describing the singularity spectrum (Hentschel and Procaccia 1983; Vidal-Vazquez et al. 2013; Yakimov et al. 2014; Paz-Ferreiro et al. 2018; Siqueira et al. 2018). Thus, multifractal analysis allows describing the spatial structure of a community, since the method is directly linked to the quantification and spatial distribution of the soil fauna, which is modified by agriculture.

Based on the described above, the objectives of this work were: a) to determine the biological diversity of the edaphic fauna in an area with natural vegetation and in agricultural systems; b) to describe the intrinsic variability of the biological diversity indexes in the areas of study based on multifractal analysis.

\section{MATERIAL AND METHODS Area of study}

The study was conducted in the municipality of Mata Roma, state of Maranhão, Brazil, at the coordinates $3^{\circ} 70^{\prime} 80.88^{\prime \prime} \mathrm{S}$ and $43^{\circ} 18^{\prime} 71.27^{\prime \prime}$ W. The soil in the region is classified as Oxisol (USDA 1999), and its physical and chemical characteristics are shown in Table 1. The climate in the region is tropical humid, the temperature varies from 27 to $30^{\circ} \mathrm{C}$ and the region has two well defined seasons, one dry and one rainy (Silva et al. 2019). The precipitation in this region ranges from 1,400 to $1,600 \mathrm{~mm}$ and annual evapotranspiration of $1,114 \mathrm{~mm}^{3}$.

The experiment was carried out in the following areas: millet ( $90.53 \mathrm{ha})$, maize (71.51 ha), soybean ( $90.35 \mathrm{ha})$, eucalyptus (5.71 ha), preserved cerrado (19.35 ha) and disturbed cerrado (49.13 ha). The areas with millet, maize and soybean crops, adopted a no-tillage system, initiated in 2007 . These areas have been cultivated with maize and soybean in alternating years, followed by the cultivation of millet at the end of each cropping season as a soil conservation technique. The soil in these areas also has been submitted to subsolation up to $0.32 \mathrm{~m}$ deep in order to increase soil water infiltration and decrease compaction. The area with soybean was submitted to the application of leaf desiccant on at May 7, 2015.

The area with eucalyptus has been cultivated since 2009 and, at the moment of the samplings, the soil cover was close to $90 \%$, with the presence of litter, consisting mainly of leaves and eucalyptus branches, from previous pruning. The organic matter content in this area was $27 \mathrm{~g} \cdot \mathrm{dm}^{-3}$ (Table 1 ).

The areas with natural vegetation comprise two fragments of cerrado (stricto sensu). The natural vegetation with cerrado in the region has different vegetal strata, with a diverse floristic composition. The area of preserved cerrado corresponds to a natural reserve, obeying the criteria of the Brazilian legislation. The disturbed cerrado comprises an area used during the dry period as pasture for cattle.

The pasture area is used for goat and sheep grazing, with a density of 0.04 ha. This area was cultivated until 2014 with rotation of soybean and maize and in 2015 was exclusively separated for animal grazing with predominance of grass species native to the region, and at the time of sampling the soil was $80 \%$ covered. 
Table 1. Physicochemical characterization of the areas of study (preserved cerrado and disturbed cerrado) and management (millet, maize, soybean, and eucalyptus) of the soil.

\begin{tabular}{|c|c|c|c|c|c|c|c|c|c|c|c|}
\hline \multirow{2}{*}{ Areas } & \multirow{2}{*}{ Coordinates } & Clay & Silt & Sand & $\mathrm{OC}$ & $\mathrm{P}$ & \multirow{2}{*}{$\begin{array}{c}\mathrm{pH} \\
\left(\mathrm{CaCl}_{2}\right)\end{array}$} & $\mathrm{K}^{+}$ & $\mathrm{Ca}^{2+}$ & $\mathrm{Mg}^{2+}$ & CEC \\
\hline & & \multicolumn{3}{|c|}{$\mathrm{g} \cdot \mathrm{kg}^{-1}$} & \multicolumn{2}{|c|}{$\mathrm{g} \cdot \mathrm{dm}^{-3}$} & & \multicolumn{4}{|c|}{$\mathrm{mmol}_{\mathrm{c}} \cdot \mathrm{dm}^{-3}$} \\
\hline Millet & $\begin{array}{c}3^{\circ} 69^{\prime} 21.18^{\prime \prime} \mathrm{S} \\
43^{\circ} 19^{\prime} 49.31^{\prime \prime} \mathrm{W}\end{array}$ & 120 & 110 & 770 & 29 & 18 & 4.6 & 2.2 & 20 & 4 & 51.2 \\
\hline Maize & $\begin{array}{c}3^{\circ} 70^{\prime} 39.32 \text { " S } \\
43^{\circ} 18^{\prime} 52.72 " \mathrm{~W}\end{array}$ & 147 & 107 & 746 & 19 & 14 & 5.0 & 2.4 & 26 & 5 & 56.4 \\
\hline Soybean & $\begin{array}{c}3^{\circ} 70^{\prime} 35.2 \text { " S } \\
43^{\circ} 19^{\prime} 11.95^{\prime \prime} \mathrm{W}\end{array}$ & 180 & 70 & 750 & 22 & 49 & 5.0 & 0.7 & 18 & 3 & 46.7 \\
\hline Eucalyptus & $\begin{array}{c}3^{\circ} 70^{\prime} 91.90 " \mathrm{~S} \\
43^{\circ} 18^{\prime} 86.83^{\prime \prime} \mathrm{W}\end{array}$ & 257 & 56 & 687 & 27 & 10 & 4.7 & 0.3 & 14 & 5 & 54.3 \\
\hline $\begin{array}{l}\text { Preserved } \\
\text { cerrado }\end{array}$ & $\begin{array}{c}3^{\circ} 69^{\prime} 22.46 " \mathrm{~S} \\
43^{\circ} 18^{\prime} 88.76^{\prime \prime} \mathrm{W}\end{array}$ & 261 & 58 & 681 & 15 & 7 & 4.1 & 0.2 & 2 & 1 & 35.2 \\
\hline $\begin{array}{l}\text { Disturbed } \\
\text { cerrado }\end{array}$ & $\begin{array}{c}3^{\circ} 71^{\prime} 09.76 " \mathrm{~S} \\
43^{\circ} 18^{\prime} 84.02 " \mathrm{~W}\end{array}$ & 256 & 77 & 667 & 21 & 8 & 4.2 & 0.5 & 3 & 3 & 42.5 \\
\hline Pasture & $\begin{array}{c}3^{\circ} 70^{\prime} 70.68^{\prime \prime} \mathrm{S} \\
43^{\circ} 18^{\prime} 13.82^{\prime \prime} \mathrm{W}\end{array}$ & 232 & 68 & 700 & 18 & 12 & 5.3 & 2.2 & 22 & 8 & 55.2 \\
\hline
\end{tabular}

OC: organic carbon; P: phosphorus; K: potassium; Ca: calcium; Mg: magnesium; CEC: cation exchange capacity.

\section{Biological sampling}

The soil fauna was simultaneously sampled in all treatments on May 12, 2015, using pitfall traps in transects at a $3 \mathrm{~m}$ spacing. One hundred and thirty traps were installed in each treatment. These traps contained $200 \mathrm{~mL}$ of $4 \%$ formalin and were set according to the methodology described by Aquino (2001). The traps remained in the field for a period of seven days, and the collected organisms were screened and identified at the level of large groups (orders). Table 2 shows the total number of organisms per taxonomic group and by treatment (millet, maize, soybean, eucalyptus, preserved cerrado, disturbed cerrado and pasture).

Table 2. Taxonomic groups, total number and number of individuals per treatment.

\begin{tabular}{|c|c|c|}
\hline Taxonomics groups & Total number & Number of individuals per treatment \\
\hline Acari & 7,706 & $\begin{array}{l}\text { Millet (5,772), maize (311), soybean ( } 71 \text { ), eucalyptus (594), preserved } \\
\text { cerrado (202), disturbed cerrado (7) and pasture (749) }\end{array}$ \\
\hline Araneae & 2,769 & $\begin{array}{l}\text { Millet (2), maize (13), soybean (33), eucalyptus (192), preserved cerrado } \\
(1,592) \text {, disturbed cerrado (853) and pasture (84) }\end{array}$ \\
\hline Coleoptera & 1,060 & $\begin{array}{l}\text { Millet (602), maize (134), soybean (30), eucalyptus (81), preserved } \\
\text { cerrado (43), disturbed cerrado (32) and pasture (138) }\end{array}$ \\
\hline Diplura & 828 & $\begin{array}{l}\text { Millet (51), maize (19), soybean (9), eucalyptus (354), preserved cerrado } \\
\text { (182), disturbed cerrado (197) and pasture (16) }\end{array}$ \\
\hline Dermaptera & 3,961 & $\begin{array}{l}\text { Millet (3317), maize (76), soybean (41), eucalyptus (2), preserved cerrado } \\
(0) \text {, disturbed cerrado (0) and pasture (525) }\end{array}$ \\
\hline Diptera & 122 & $\begin{array}{c}\text { Millet (4), maize (2), soybean (12), eucalyptus (2), preserved cerrado (1), } \\
\text { disturbed cerrado (0) and pasture (101) }\end{array}$ \\
\hline Diplopoda & 19 & $\begin{array}{c}\text { Millet (0), maize (2), soybean (0), eucalyptus (13), preserved cerrado (4), } \\
\text { disturbed cerrado (0) and pasture (0) }\end{array}$ \\
\hline Formicidae & 1,821 & $\begin{array}{l}\text { Millet (106), maize (215), soybean (11), eucalyptus (428), preserved } \\
\text { cerrado (248), disturbed cerrado (588) and pasture (225) }\end{array}$ \\
\hline Hymenoptera & 175 & $\begin{array}{l}\text { Millet (11), maize (4), soybean (14), eucalyptus (49), preserved cerrado } \\
\text { (38), disturbed cerrado (23) and pasture (36) }\end{array}$ \\
\hline Gastropoda & 2 & $\begin{array}{c}\text { Millet }(0) \text {, maize (0), soybean ( } 0) \text {, eucalyptus ( } 1 \text { ), preserved cerrado (1), } \\
\text { disturbed cerrado }(0) \text { and pasture }(0)\end{array}$ \\
\hline
\end{tabular}


Table 2. Continuation...

\begin{tabular}{|c|c|c|}
\hline Taxonomics groups & Total number & Number of individuals per treatment \\
\hline Isopoda & 16 & $\begin{array}{c}\text { Millet (0), maize (0), soybean ( } 0 \text { ), eucalyptus ( } 16) \text {, preserved cerrado ( } 0 \text { ), } \\
\text { disturbed cerrado ( } 0 \text { ) and pasture ( } 0)\end{array}$ \\
\hline Isoptera & 65 & $\begin{array}{c}\text { Millet (0), maize (0), soybean ( } 0 \text { ), eucalyptus ( } 0 \text { ), preserved cerrado (11), } \\
\text { disturbed cerrado (54) and pasture ( } 0 \text { ) }\end{array}$ \\
\hline Lepidoptera larvae & 57 & $\begin{array}{l}\text { Millet (2), maize (2), soybean (0), eucalyptus (2), preserved cerrado (1), } \\
\text { disturbed cerrado }(0) \text { and pasture (54) }\end{array}$ \\
\hline Orthoptera & 17 & $\begin{array}{l}\text { Millet (5), maize (1), soybean (0), eucalyptus (0), preserved cerrado ( } 2 \text { ), } \\
\text { disturbed cerrado ( } 0 \text { ) and pasture ( } 9 \text { ) }\end{array}$ \\
\hline Entomobryomorpha & 60 & $\begin{array}{c}\text { Millet (49), maize (11), soybean ( } 0 \text { ), eucalyptus (0), preserved cerrado (0), } \\
\text { disturbed cerrado }(0) \text { and pasture }(0)\end{array}$ \\
\hline Psocoptera & 48 & $\begin{array}{l}\text { Millet (43), maize (5), soybean ( } 0 \text { ), eucalyptus ( } 0 \text { ), preserved cerrado ( } 0 \text { ), } \\
\text { disturbed cerrado }(0) \text { and pasture }(0)\end{array}$ \\
\hline Trichoptera & 8 & $\begin{array}{l}\text { Millet (2), maize (1), soybean ( } 0) \text {, eucalyptus ( } 3 \text { ), preserved cerrado ( } 0) \text {, } \\
\text { disturbed cerrado ( } 2 \text { ) and pasture }(0)\end{array}$ \\
\hline Poduromorpha & 2,159 & $\begin{array}{c}\text { Millet (8), maize (1), soybean (1), eucalyptus }(2,098) \text {, preserved cerrado } \\
(45) \text {, disturbed cerrado }(6) \text { and pasture }(0)\end{array}$ \\
\hline Scorpionida & 21 & $\begin{array}{c}\text { Millet (0), maize (0), soybean (0), eucalyptus ( } 2 \text { ), preserved cerrado (5), } \\
\text { disturbed cerrado (14) and pasture ( } 0 \text { ) }\end{array}$ \\
\hline Sternorrhyncha & 40 & $\begin{array}{l}\text { Millet (0), maize (27), soybean (0), eucalyptus (4), preserved cerrado (9), } \\
\text { disturbed cerrado ( } 0 \text { ) and pasture ( } 0)\end{array}$ \\
\hline Thysanura & 1 & $\begin{array}{c}\text { Millet (0), maize (0), soybean ( } 0 \text { ), eucalyptus ( } 0) \text {, preserved cerrado ( } 0) \text {, } \\
\text { disturbed cerrado ( } 1 \text { ) and pasture }(0)\end{array}$ \\
\hline Total & & 20,955 \\
\hline
\end{tabular}

\section{Indexes of biological diversity}

The indexes of individuals.trap ${ }^{-1} \cdot$ day $^{-1}$, richness, Shannon-Wiener diversity and Pielou equitability were determined according to the methodology described by Magurran (2004).

The index of individuals $\cdot$ trap $^{-1} \cdot$ day $^{-1}$ corresponds to the number of individuals collected in each trap per day. The index of richness estimates the richness of a community. It is defined as a function of the number of species that occur in only one sample, termed single species. Thus, the larger the number of species in a single sample, the higher the estimate for the total number of species in the community (Eq. 1).

$$
E D=S_{o b s}+S_{1}\left(\frac{f-1}{f}\right)
$$

where $S_{o b s}$ is the number of observed species; $S_{1}$ the number of species present in a single cluster; and $f$ the number of samples.

The Shannon-Wiener diversity index is the most commonly used in community studies. . The index will be zero if a sample contains only one species and reaches the maximum value when all species of a sample have the same number of individuals (Eq. 2).

$$
H^{\prime}=-\sum_{i=1}^{n} p_{i} \cdot \log _{2} p_{i}
$$

where $n i=$ number of individuals of species $i$ in the sample; $N=$ total number of individuals in the sample; $\log _{2}=\operatorname{logarithm}$ (base 2). 
The Pielou equitability indicates the distribution of individuals among species and is proportional to diversity and inversely proportional to dominance. Equitability compares the Shannon-Wiener diversity with the observed species distribution that maximizes diversity (Eq. 3).

$$
U=\frac{H^{\prime}}{\log _{2} S}
$$

where $H^{\prime}$ is the Shannon-Wiener index; $S$ the number of groups present in each area; and $\log$ the logarithm (base 2).

\section{Multifractal analysis}

The method of moment was used to determine the multifractal parameters of the soil fauna. A transect of $381 \mathrm{~m}$ was divided into successive smaller segments, generating partition functions in $k(k=1,2,3 \ldots)$ and generating scales of $\delta$ segment numbers, $N(\delta)=2^{k}$ of characteristic length, $\delta=L \times 2^{-k}$ (Evertsz and Mandelbrot 1992; Vidal-Vázquez et al. 2013).

The indexes of the soil were converted to a mass function, $p i(\delta)=\mu_{i}(\delta)$, where a $p i(\delta)$ is the variable that describes the contribution of a segment or subintervals of size $\delta$ to the total mass total. This estimate was calculated by Eq. 4 :

$$
p_{i}(\delta)=\varphi_{i}(\delta) / \sum_{i=1}^{n(\delta)} \varphi_{i}(\delta)
$$

where $\varphi_{i}$ is the value of the measure in the $i^{\text {th }}$ segment in scale $\delta ; n(\delta)$ is the number of segments with size $\delta$, which covers the sample space; and $\sum_{i=1}^{n(\delta)} \varphi_{i}(\delta)$ represents the total mass of the entire transect under analysis.

Subsequently, estimations of various scaling functions for all data of fauna, exponential mass $(\tau q)$, singularity spectrum $\left(\mathrm{f}(\alpha)\right.$ ), scale index $\left(\alpha_{q}\right)$ and generalized or Rényi dimension $\left(D_{q}\right)$ were determined. The partition function resulting from the weighted sum was defined by Eq. 5 .

$$
\chi(q, \delta)=\sum_{i=1}^{n(\delta)} p_{i_{i}} q(\delta)
$$

wherein $n(\delta)$ is the number of segments with size $\delta$ and statistical moments that are defined for $-\infty<q<\infty$.

The mass function, estimated by the partition function, is obtained by Eq. 6 , where the function $\tau_{q}$ controls the measurement moment $\mu_{i}$ in $q$. In this case, when the measurements are multifractal a nonlinear function of $\tau_{q}$ is produced, whereas for monofractal measurements the function of $\tau_{q}$ is a linear function.

$$
\tau(q)=\lim _{\delta=0} \frac{\log \chi(q, \delta)}{\log (1 / \delta)}
$$

For the segments in question, the distribution probability is characterized by: where $\alpha_{i}$ is the singularity or the Hölder's exponent of density characterization in the $\mathrm{n}^{\text {th }}$ box. This exponent corresponds to an agglomeration index for the concentration degree of measure $\mu$ and is given by $\alpha_{i}=\log \mu_{i}(\delta) / \log \delta$.

For multifractal measures, $N_{\delta}(\alpha)$ of cells of size $\delta$, having a singularity or the Hölder's exponent equal to $\alpha$ increases for the decrease of $\delta$ and obeys to a law power: $N(\alpha)$, where the exponent $f(\alpha)$ is a continuous function of $\alpha$. The spectrum graph $f(\alpha)$ versus $\alpha$, is a concave parabola, where the value interval increases upon the increasing of the measure heterogeneity, and is obtained by Eqs. 7 and 8. However, it is worth mentioning that the exponents of scales $\tau_{q}$ and $f(\alpha)$ can be obtained 
by means of a Legendre transformation, however, it has several disadvantages, such as greater error in the estimation of $f(\alpha)$ and $\alpha$ in negative moments. For the present study, scales $\tau_{q}$ and $f(\alpha)$ were estimated by methodologies described by Chhabra and Jensen (1989). Values of $f(\alpha)$ versus $\alpha$ calculated by Eqs. 7 and 8 were accepted with coefficient of determination, $\mathrm{R}^{2} \geq 0.90$.

$$
\begin{gathered}
\alpha(q) \propto \sum_{i=1}^{n(\delta)} \frac{\mu_{i}(q, \delta) \log \left(p_{i}(\delta)\right)}{\log (\delta)} \\
f(\alpha(q))=\propto \sum_{i=1}^{n(\delta)} \frac{\mu_{i}(q, \delta) \log \left(\mu_{i}(q, \delta)\right)}{\log (\delta)}
\end{gathered}
$$

The multifractal measurements can be characterized by the generalized or Rényi dimension of order $q, D_{q}$ (Hentschel and Procaccia 1983), and is described by Eq. 9 , for $q \neq 1$, and by Eq. 10, for $q=1$.

$$
\begin{gathered}
D_{q}=\frac{1}{q-1} \lim _{\delta \rightarrow 0} \frac{\log (\chi(q, \delta))}{\log (\delta)}=\frac{\tau(q)}{q-1}, \quad q \neq 1 \\
D_{1}=\lim _{\delta \rightarrow 0}\left[\sum_{i=1}^{n(\delta)} \frac{p_{i}(\delta) \log \left(p_{i}(\delta)\right)}{\log (\delta)}\right], \quad q=1
\end{gathered}
$$

The generalized dimensions, $D_{q}$ for $q=0, q=1$ and $q=2$, are referred to as capacity dimension, entropy dimension or Shannon entropy as well as correlation dimension. For multifractal, generalized dimensions must conform to specific characteristics, such as $\mathrm{D}_{0}>\mathrm{D}_{1}>\mathrm{D}_{2}$. In case where the measure is monofractal, no dependence of $q$ is expected. In the present analysis, the generalized dimension $D_{q}$ was calculated in the range of statistical moments $-10 \leq q \leq 10$ in the range of 1.0 .

\section{RESULT AND DISCUSSION Soil fauna}

The highest average $(\overline{\mathrm{X}})$ of individuals was observed in the area cultivated with millet $(\overline{\mathrm{X}}=76,723)$, followed by eucalyptus $(\overline{\mathrm{X}}=29,546)$, preserved cerrado $(\overline{\mathrm{X}}=18,338)$, pasture $(\overline{\mathrm{X}}=14,869)$, disturbed cerrado $=13,669)$, maize $(\overline{\mathrm{X}}=6,338)$, and Soybean $(\overline{\mathrm{X}}=1,708)$ (Table 3$)$.

The number of individuals $\cdot \operatorname{trap}^{-1} \cdot$ day $^{-1}$ was higher in the areas with millet (individuals $\cdot \operatorname{trap}^{-1} \cdot$ day $^{-1}=1,424.81$ ) and eucalyptus (individuals $\cdot$ trap $^{-1} \cdot$ day $^{-1}=548.71$ ), explained by the presence of canopy in these areas of cultivation (Gholami et al. 2017). Mueller et al. (2015), studying soil fauna in tree systems, identified that the availability of canopy-related light is an important predictor for characterizing invertebrate richness.

Biological diversity was higher for soybean area (Shannon $=2.69)$, followed by maize (Shannon $=2.42$ ), pasture Shannon $=2.42)$, eucalyptus $($ Shannon $=2.08)$, disturbed cerrado $($ Shannon $=1.85)$, millet $($ Shannon $=1.44)$ and preserved cerrado (Shannon $=0.73$ ). Studying soil fauna in agroforestry systems, Martins et al. (2018) found Shannon values ranging from 1.401 to 1.877 . This demonstrates that the diversity values for the present study are superior to those of Martins et al. (2018). The use of the Shannon index to evaluate diversity is conditioned by the comparison between studies, however, there is a lack of studies in the region, justifying the importance of the present study.

The Shannon diversity considers the number of individuals per sample and the total number of individuals in the area (Magurran, 2004). In this case, although the area with soybean had presented a lower number of individuals, 
the distribution among the different taxonomic classes is homogeneous, and there was not dominance of any group (Table 2). This corroborates the high estimate of the Pielou equitability in the soybean area.

The estimates of the Shannon and Pielou indexes were higher in the disturbed cerrado compared to the preserved cerrado. The area of disturbed cerrado has been used for grazing during the dry season, providing a differentiated environment (Korboulewsky et al. 2016), with clearings and deposition of excreta, providing a higher occurrence of individuals, which justifies the results found in this study (Table 2). García-Segura et al. (2018) also found higher diversity and richness in a disturbed area when compared to natural vegetation.

The data presented high values of coefficient of variation (CV > 60\%). This explains the occurrence of lognormal frequency distribution for the data, which was evaluated using the Kolmogorov-Smirnov test $(\mathrm{D}=\mathrm{p}<0.01)$, except the areas with millet and maize that had normal distribution.

The normality of data in the millet and maize areas was expected, since these treatments did not receive cultural treatments after planting, allowing the development of soil fauna organisms, whereas in the area cultivated with soybean was applied desiccant, which decreased the shading and consequently the number of organisms. However, the normality of data is not required for multifractal analysis, and the most important aspect for this analysis is that values are distributed in successive segments (Mandelbrot, 1982).

\section{Multifractal analysis}

The partition functions constructed for successive segments of $2^{k}$ where $k=0$ to $k=8$ and for the order moments $-10<q<10$ with the best and worst settings for the determination coefficient $\left(\mathrm{R}^{2}\right)$ are shown in Fig. 1. The area with millet had the best adjustment for the Richness index $\left(\mathrm{R}^{2}=0.999\right)$ and the worst adjustment for Pielou equitability $\left(R^{2}=0.989\right)$, as shows Fig. 1. The partition function expressed the scale structure of the variable, where simple scales can be used, in this case, a monofractal or multiple scales for multifractal behavior (Siqueira et al. 2018; Vidal-Vázquez et al. 2013). The better adjustment of the partition function for the richness index in the area with millet reflects the greater abundance of individuals observed in this area (9,974 individuals). On the other hand, the worst adjustment for the Shannon diversity index in the area of soybean (222 individuals) shows that the management had an effect on the abundance of the organisms, since the sampling was carried out after application of desiccant to soybean.

The generalized dimensions are presented in Table 4. The differences between $\mathrm{D}_{-10}-\mathrm{D}_{10}$ ranged from $\mathrm{D}_{-10}-\mathrm{D}_{10}$ $=0.080$, for the Pielou equitability in the area with soybean, to $\mathrm{D}_{-10}-\mathrm{D}_{10}=1.707$, for the richness in the area with eucalyptus.

The difference $\mathrm{D}_{-10}-\mathrm{D}_{10}$ indicates multifractality, as reported by Vidal-Vázquez et al. (2008); Vidal-Vázquez et al. (2013) and Dafonte et al. (2015). On the other hand, richness expresses the highest degree of multifractality among the biological diversity indexes evaluated. Thus, this study shows that the simpler the index, the greater its multifractality. According to Gholami et al. (2017), the soil macrofauna can be evaluated by different methodologies, with the sole purpose of characterizing the richness, allowing to describe a series of functional aspects of soil biodiversity.

The capacity dimension $\left(\mathrm{D}_{0}\right.$, Table 4$)$ for millet had invariable values $\left(\mathrm{D}_{0}=1.000 \pm 0.000\right)$ for all indexes. Invariable values of $\mathrm{D}_{0}$ were also reported by Dafonte et al. (2015) in a study of soil chemical attributes. This demonstrates that $\mathrm{D}_{0}$ tends to be equal to or close to 1,000 for most variables, expressing values close to a monoscale. According to Banerjee et al. (2011), $\mathrm{D}_{0}$ values describe the overall homogeneity of the data. This justifies the reason why the area with millet had values of $\mathrm{D}_{0}$ equal to 1,000 , since in this treatment the individuals of the soil fauna occurred in a homogeneous way along the transect, and consequently in the segments. The maize, soybean and eucalyptus areas showed the lowest values of $\mathrm{D}_{0}$, reflecting the lower occurrence of taxonomic groups along the transect. The diversity indexes for the areas of preserved cerrado and disturbed cerrado had values of $\mathrm{D}_{0}$ equal or close to 1,000 , demonstrating 
that in these areas the systems are homogeneous, however with heterogeneity determined by the stabilization of the trophic chain.

The lowest values of information dimension or Shannon entropy $\left(D_{1}\right)$ are described for the richness in the eucalyptus area $\left(D_{1}=0.019 \pm 0.007\right)$ and Pielou equitability in the soybean area $\left(D_{1}=0.806 \pm 0.031\right)$. The information dimension evaluates the disorder distribution of values of a variable, ranging between $0<\mathrm{D}_{1}<1$ (Gouyet 1996). Upon this, the area with eucalyptus had the greatest disorder of the values in the segments, which correspond to the eight partitions described in Fig. 1.

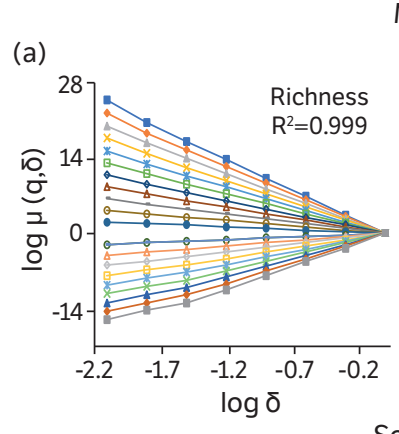

Millet

(b)

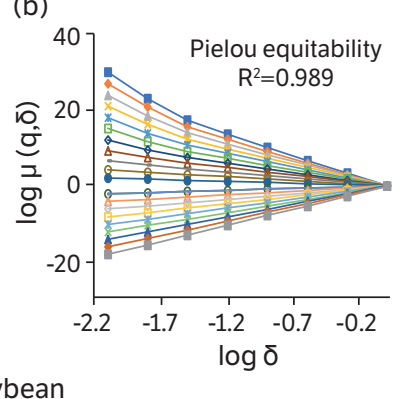

(e)

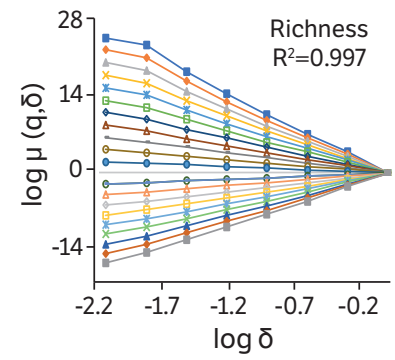

(f)

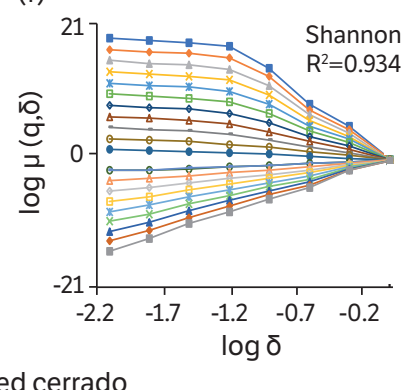

(i)

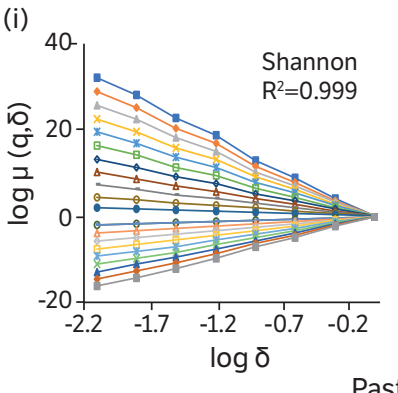

Pasture

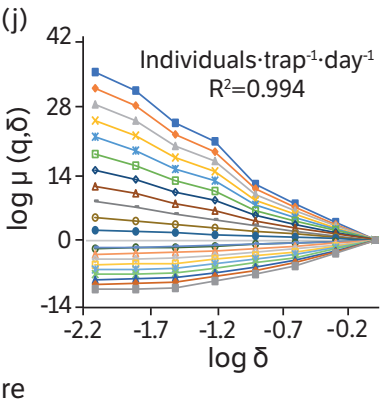

(n)

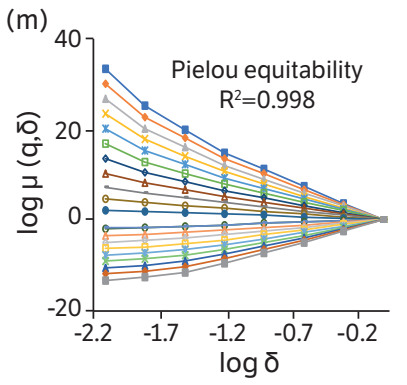

(c)

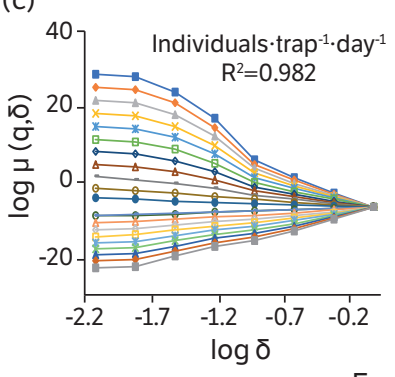

Eucalyptus

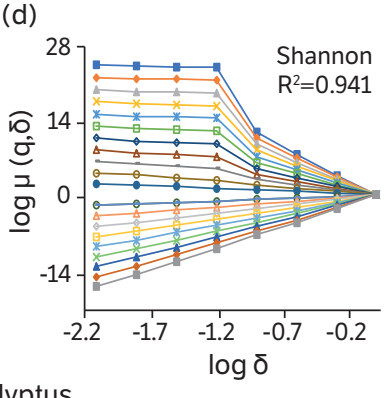

(g)

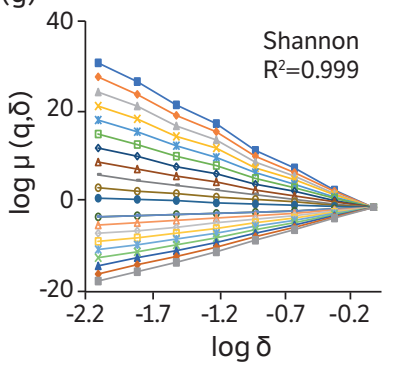

(h)

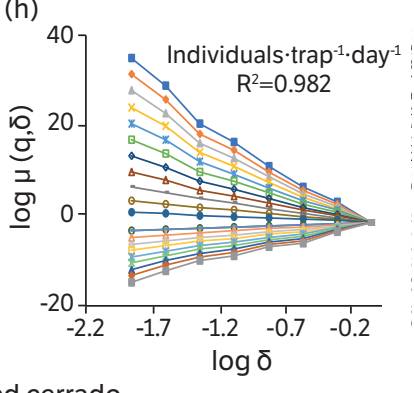

(k)

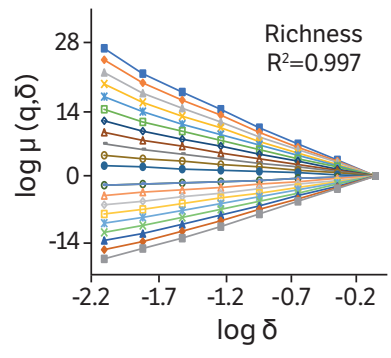

(I)

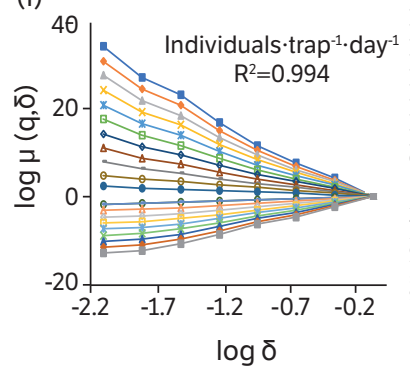

Figure 1. Partition function for soil fauna indexes in different uses and management. (a) Richness and (b) Pielou equitability (millet); (c) Individuals.trap ${ }^{-1} \cdot$ day $^{-1}$ and (d) Shannon (maize); (e) Richness and (f) Shannon (soybean); (g) Shannon and (h) Individuals trap ${ }^{-1} \cdot$ day $^{-1}$ (eucalyptus); (i) Shannon and (j) Individuals.trap ${ }^{-1}$.day ${ }^{-1}$ (preserved cerrado); (k) Richness and (I) Individuals.trap ${ }^{-1}$.day ${ }^{-1}$ (disturbed cerrado); (m) Equitability and $(n)$ Individuals $\cdot$ trap $^{-1} \cdot$ day $^{-1}$ (pasture). 
Table 3. Statistics indexes and parameters for the fauna in the areas of study (preserved cerrado and disturbed cerrado) and management (millet, maize, soybean, and eucalyptus) of the soil.

\begin{tabular}{|c|c|c|c|c|c|c|c|}
\hline & Millet & Maize & Soybean & Eucalyptus & $\begin{array}{c}\text { Preserved } \\
\text { cerrado }\end{array}$ & $\begin{array}{c}\text { Disturbed } \\
\text { cerrado }\end{array}$ & Pasture \\
\hline \multicolumn{8}{|c|}{ Biological diversity indexes } \\
\hline Number of individuals & 9,974 & 824 & 222 & 3,841 & 2,384 & 1,777 & 1,933 \\
\hline Individuals trap $^{-1} \cdot$ day $^{-1}$ & $1,424.85$ & 117.71 & 31.71 & 548.71 & 340.57 & 253.85 & 276.14 \\
\hline Richness & 14 & 16 & 9 & 16 & 15 & 11 & 10 \\
\hline Shannon & 1.44 & 2.42 & 2.69 & 2.08 & 0.73 & 1.85 & 2.42 \\
\hline Pielou & 0.37 & 0.60 & 0.84 & 0.52 & 0.44 & 0.53 & 0.73 \\
\hline \multicolumn{8}{|c|}{ Statistics parameters } \\
\hline Mean & 76.723 & 6.338 & 1.708 & 29.546 & 18.338 & 13.669 & 14.869 \\
\hline Standard deviation & 50.863 & 5.870 & 1.067 & 33.137 & 28.293 & 15.427 & 13.264 \\
\hline $\mathrm{CV}(\%)$ & 66.294 & 92.611 & 62.488 & 112.154 & 154.285 & 112.863 & 89.203 \\
\hline Skew & 1.163 & 2.048 & 1.659 & 2.325 & 4.255 & 2.800 & 2.809 \\
\hline Kurtosis & 1.447 & 6.613 & 2.999 & 6.202 & 26.574 & 9.463 & 10.149 \\
\hline$D^{\star}$ & $0.114 n$ & $0.14 n$ & $0.308 \operatorname{Ln}$ & $0.225 \mathrm{Ln}$ & $0.258 \operatorname{Ln}$ & $0.266 \operatorname{Ln}$ & $0.208 \mathrm{Ln}$ \\
\hline
\end{tabular}

CV (\%): coefficient of variation; n: normal; Ln: Lognormal; $D^{\star}$ : normality Kolmogorov-Smirnov $(p<0.01)$.

The correlation dimension $\left(\mathrm{D}_{2}\right)$ refers to the correlation at the different intervals, so the richness in the area with eucalyptus expressed the lowest correlation between segments $\left(\mathrm{D}_{2}=0.007 \pm 0.003\right)$. The highest values of $\mathrm{D}_{2}$ corresponded to the richness $\left(D_{2}=0.992 \pm 0.001\right)$ and Pielou equitability $\left(D_{2}=0.989 \pm 0.002\right)$ in the area with millet. The area of millet had greater abundance and dominance of Acari, however, the abundance of this taxon is not conditioned only to a sample in the 128 points, its distribution is uniform throughout the transept.

According to Banerjee et al. (2011), Vidal-Vazquéz et al (2013), Dafonte et al. (2015), and Siqueira et al. (2018), a relation $\mathrm{D}_{0}>\mathrm{D}_{1}>\mathrm{D}_{2}$ must occur for a system to be multifractal, evidencing different degrees of multifractality. In this study, all the treatments expressed multifractality following the relation $\mathrm{D}_{0}>\mathrm{D}_{1}>\mathrm{D}_{2}$.

The values of the singularity spectra, $f(\alpha)$ versus $\alpha$ for $q^{-}, q+, \alpha_{0}, \alpha_{10}$ and $\alpha_{-10}$ (Table 3) varied between the indexes. The Hölder's exponent $\left(\alpha_{0}\right)$ was lower for the area with soybean: individuals trap ${ }^{-1}$.day ${ }^{-1}\left(\alpha_{0}=1024 \pm 0.004\right)$; richness $\left(\alpha_{0}=0.818\right.$ $\pm 0.111)$; Shannon $\left(\alpha_{0}=872 \pm 0.086\right)$ and Pielou equitability $\left(\alpha_{0}=0.820 \pm 0.107\right)$, result of the low abundance of individuals in this area. The area with eucalyptus had values of $\alpha_{0}$ greater than 1,000 , indicating that the fauna of the soil in this area is more diverse (Shannon $-\alpha_{0}=1,132 \pm 0,038$ ). The occurrence of higher numbers of invertebrates in the area with eucalyptus can be explained by the higher content of organic material (Table $1-\mathrm{OM}=27 \mathrm{~g} \cdot \mathrm{dm}^{-3}$ ) (Wardle et al. 2006; Silva et al. 2018). This justifies the dominance of Collembola, which, according to Bardgett and van der Putten (2015), are organisms that only develop in favorable environments with high content of organic matter. On the other hand, at studying the abundance of the soil macrofauna and its relationship with the management and quantity of cultural residues, Paul et al. (2015) did not find significant results that the management contributed to increase the macrofauna. However, Mueller et al. (2015), in a study evaluating the soil macrofauna and predictors of biodiversity, described that the availability of resources regulates the macrofauna.

The graph of the singularity spectrum showed a well-structured pattern with asymmetric branches, especially for the richness index (Fig. 2), confirming the greater multifractality and homogeneity of the data series, uniformly distributed and correlated. Yakimov et al. (2014) described that multifractality in a meadow, whose richness was sampled at different scales, had a singularity spectrum with greater or lesser heterogeneity of the branches defined by the sample size. Yakimov et al. (2018), studying the multifractality of species richness, described that multifractal systems are influenced by the diversity and abundance of species, reflecting on the homogeneity or heterogeneity of the systems.

Shannon diversity and Pielou equitability indexes showed a monofractal tendency (Fig. 2c and d), describing that the complexity for the determination of such indexes tends towards a system homogeneity, since the Shannon diversity calculation considers number 
of individuals in the sample in relation to the total occurrence of individuals in the studied area, using logarithmic transformation. The amplitude and asymmetry of the singularity spectrum are indicative of heterogeneity in the database (Paz-Ferreiro et al. 2018), providing information on the scale measures of the variable (Yakimov et al. 2018). Figure 2 shows that all the biological diversity indexes in the study present different degrees of asymmetry for the datasets, and the richness index showed the highest homogeneity, except in soybean and millet areas (Fig. 2b). The singularity spectrum for richness in the soybean area showed left-deviation curve, indicating dominance or presence of high values of richness at the beginning of the transect; while the richness index in the millet area showed dominance or presence of high values at the end of the transect. The singularity spectrum for individuals.trap ${ }^{-1} \cdot$ day $^{1}$ (Fig. 2a) presented left-deviation curve asymmetry for all datasets under study. The Shannon (Fig. 2c) and Pielou indexes (Fig. 2d) had different degrees of heterogeneity in the studied areas, showing a tendency or dominance of high or low values in the different areas, the multifractality of the data being influenced by the degree of perturbation of the in different treatments. The area cultivated with soybean showed a monofractal tendency for the Shannon and Pielou indexes (Fig. 2c and d), demonstrating that the fauna organisms are not necessarily in equilibrium, corroborating the study of Yakimov et al. (2018).

The results present in this study demonstrate that the multifractal analysis is a useful tool to understand the soil fauna dynamics. This tool supports the decision-making associated to the adopted management, allowing to infer about sample size or ecological issues. Multifractal technique allowed the comparison and study of the edaphic fauna in the different treatments (millet, maize, soybean, eucalyptus, preserved cerrado, disturbed cerrado and pasture), indicating that the area with soybean was the one that most influenced the soil invertebrates and the indexes of biological diversity (Marichal et al. 2014).

(a)

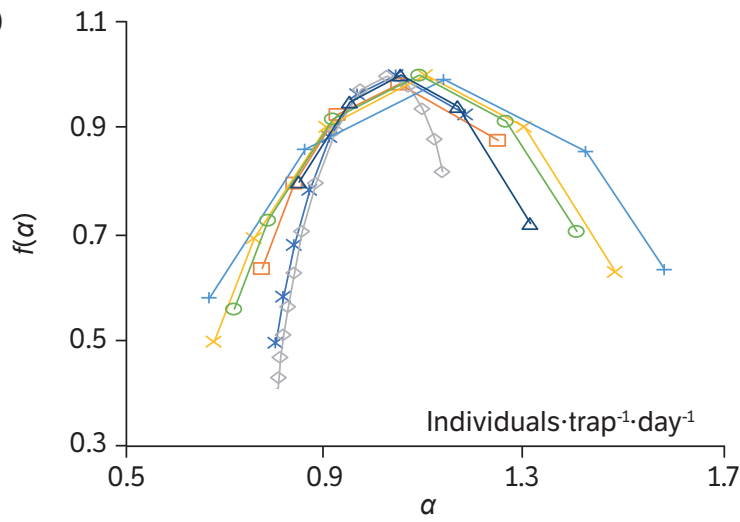

(c)

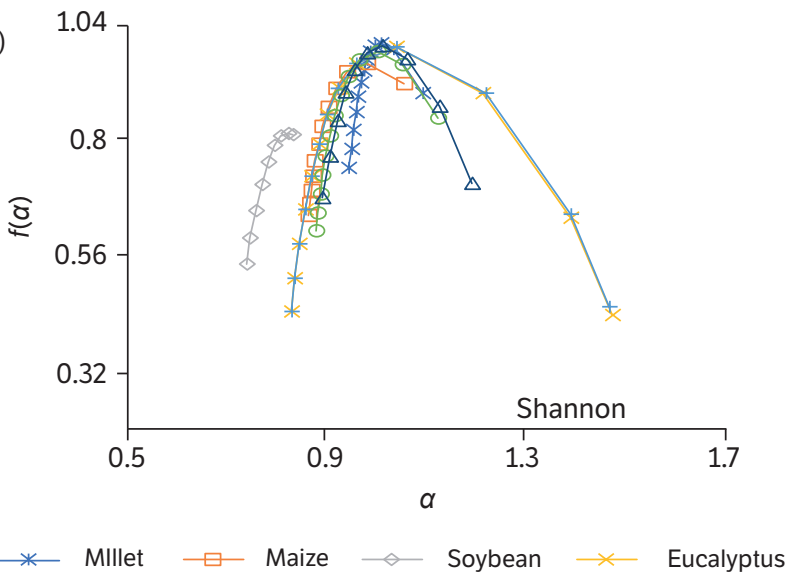

(b)

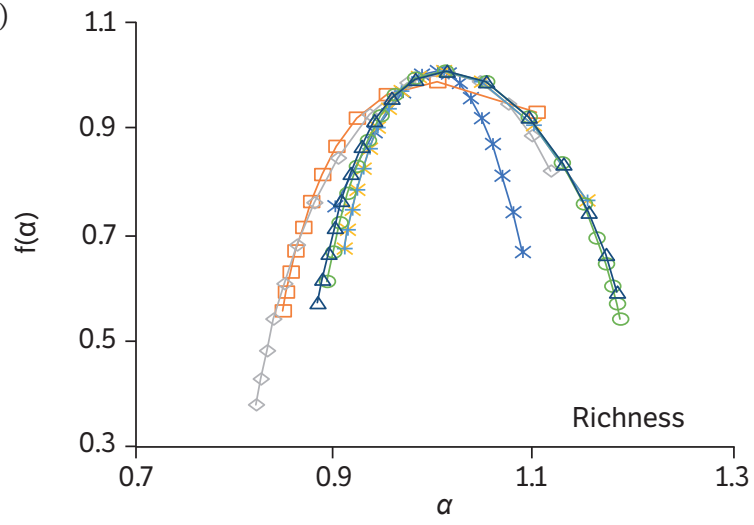

(d)

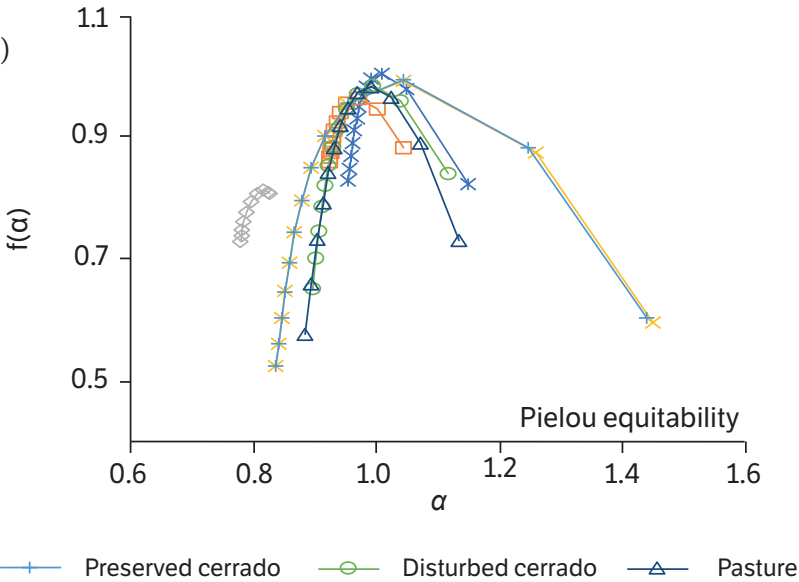

Figure 2. Singularity spectrum for soil fauna indexes in different uses and management. (a) Individuals trap-1 day-1; (b) Richness; (c) Shannon; (d) Pielou equitability. 
Table 4. Multifractal parameters obtained from the generalized dimension $\left(D_{-10}-D_{10}, D_{-10}, D_{10}, D_{0}, D_{1}\right.$ and $\left.D_{2}\right)$ and the singularity spectra $\left(q_{+}, q_{-}, \alpha_{0}, \alpha_{\max }\right.$ and $\left.\alpha_{\min }\right)$.

\begin{tabular}{|c|c|c|c|c|c|c|c|c|c|c|c|}
\hline \multicolumn{12}{|c|}{ Millet } \\
\hline & $D_{-10}-D_{10}$ & $\mathrm{D}_{-10}$ & $\mathrm{D}_{10}$ & $D_{0}$ & $\mathrm{D}_{1}$ & $\mathrm{D}_{2}$ & $q_{+}$ & q. & $\alpha_{0}$ & $\alpha_{\max }$ & $\alpha_{\min }$ \\
\hline Individuals.trap ${ }^{-1} \cdot$ day $^{-1}$ & 0.611 & $1.438 \pm 0.112$ & $0.826 \pm 0.027$ & $1.000 \pm 0.000$ & $0.963 \pm 0.008$ & $0.934 \pm 0.014$ & 6 & -1 & $1.043 \pm 0.021$ & $1.180 \pm 0.100$ & $0.801 \pm 0.062$ \\
\hline Richness & 0.125 & $1.060 \pm 0.020$ & $0.935 \pm 0.016$ & $1.000 \pm 0.000$ & $0.996 \pm 0.000$ & $0.992 \pm 0.001$ & 6 & -5 & $1.004 \pm 0.002$ & $1.068 \pm 0.044$ & $0.930 \pm 0.032$ \\
\hline Shannon-Wiener & 1.196 & $1.926 \pm 0.140$ & $0.729 \pm 0.030$ & $1.000 \pm 0.000$ & $0.869 \pm 0.002$ & $0.823 \pm 0.025$ & 5 & -1 & $1.202 \pm 0.074$ & $1.737 \pm 0.240$ & $0.722 \pm 0.059$ \\
\hline Pielou equitability & 0.285 & $1.256 \pm 0.083$ & $0.971 \pm 0.003$ & $1.000 \pm 0.000$ & $0.993 \pm 0.001$ & $0.989 \pm 0.002$ & 10 & -2 & $1.009 \pm 0.005$ & $1.160 \pm 0.132$ & $0.958 \pm 0.008$ \\
\hline \multicolumn{12}{|c|}{ Maize } \\
\hline & $D_{-10}-D_{10}$ & $\mathrm{D}_{-10}$ & $\mathrm{D}_{10}$ & $\mathrm{D}_{0}$ & $\mathrm{D}_{1}$ & $\mathrm{D}_{2}$ & $q_{+}$ & $q$ & $\alpha_{0}$ & $\alpha_{\max }$ & $\alpha_{\min }$ \\
\hline Individuals $\cdot$ trap $^{-1} \cdot$ day $^{-1}$ & 0.611 & $1.438 \pm 0.112$ & $0.826 \pm 0.028$ & $1.000 \pm 0.000$ & $0.963 \pm 0.009$ & $0.934 \pm 0.014$ & 6 & -1 & $1.043 \pm 0.021$ & $1.180 \pm 0.100$ & $0.801 \pm 0.062$ \\
\hline Richness & 0.363 & $1.258 \pm 0.128$ & $0.895 \pm 0.009$ & $0.956 \pm 0.015$ & $0.940 \pm 0.012$ & $0.930 \pm 0.010$ & 10 & -1 & $0.976 \pm 0.042$ & $1.051 \pm 0.123$ & $0.877 \pm 0.20$ \\
\hline Shannon-Wiener & 0.906 & $1.573 \pm 0.098$ & $0.667 \pm 0.029$ & $0.971 \pm 0.010$ & $0.868 \pm 0.019$ & $0.801 \pm 0.014$ & 5 & -1 & $1.094 \pm 0.017$ & $1.389 \pm 0.126$ & $0.646 \pm 0.060$ \\
\hline Pielou equitability & 0.241 & $1.153 \pm 0.171$ & $0.911 \pm 0.008$ & $0.956 \pm 0.015$ & $0.946 \pm 0.011$ & $0.939 \pm 0.010$ & 10 & -1 & $0.970 \pm 0.046$ & $1.033 \pm 0.208$ & $0.892 \pm 0.017$ \\
\hline \multicolumn{12}{|c|}{ Soybean } \\
\hline & $\mathrm{D}_{-10}-\mathrm{D}_{10}$ & $\mathrm{D}_{-10}$ & $\mathrm{D}_{10}$ & $\mathrm{D}_{0}$ & $\mathrm{D}_{1}$ & $\mathrm{D}_{2}$ & $q_{+}$ & q. & $\alpha_{0}$ & $\alpha_{\max }$ & $\alpha_{\min }$ \\
\hline Individuals.trap ${ }^{-1} \cdot$ day $^{-1}$ & 0.273 & $1.121 \pm 0.031$ & $0.848 \pm 0.016$ & $0.998 \pm 0.001$ & $0.971 \pm 0.004$ & $0.945 \pm 0.008$ & 10 & -4 & $1.024 \pm 0.004$ & $1.136 \pm 0.062$ & $0.803 \pm 0.032$ \\
\hline Richness & 0.087 & $0.855 \pm 0.116$ & $0.769 \pm 0.012$ & $0.813 \pm 0.043$ & $0.808 \pm 0.030$ & $0.803 \pm 0.022$ & 7 & -1 & $0.818 \pm 0.111$ & $0.828 \pm 0.173$ & $0.755 \pm 0.031$ \\
\hline Shannon-Wiener & 0.472 & $1.194 \pm 0.091$ & $0.722 \pm 0.023$ & $0.843 \pm 0.36$ & $0.819 \pm 0.030$ & $0.800 \pm 0.026$ & 6 & -2 & $0.872 \pm 0.086$ & $1.140 \pm 0.203$ & $0.703 \pm 0.049$ \\
\hline Pielou equitability & 0.080 & $0.859 \pm 0.111$ & $0.779 \pm 0.013$ & $0.813 \pm 0.043$ & $0.806 \pm 0.031$ & $0.800 \pm 0.023$ & 7 & -2 & $0.820 \pm 0.107$ & $0.842 \pm 0.203$ & $0.773 \pm 0.035$ \\
\hline \multicolumn{12}{|c|}{ Eucalyptus } \\
\hline & $D_{-10}-D_{10}$ & $\mathrm{D}_{-10}$ & $\mathrm{D}_{10}$ & $\mathrm{D}_{0}$ & $\mathrm{D}_{1}$ & $\mathrm{D}_{2}$ & $q_{+}$ & $q$ & $\alpha_{0}$ & $\alpha_{\max }$ & $\alpha_{\min }$ \\
\hline Individuals.trap ${ }^{-1} \cdot$ day $^{-1}$ & 0.879 & $1.527 \pm 0.081$ & $0.648 \pm 0.027$ & $0.999 \pm 0.001$ & $0.902 \pm 0.007$ & $0.823 \pm 0.012$ & 3 & -2 & $1.101 \pm 0.016$ & $1.481 \pm 0.141$ & $0.678 \pm 0.051$ \\
\hline Richness & 1.707 & $1.712 \pm 0.44$ & $0.004 \pm 0.002$ & $0.744 \pm 0.083$ & $0.019 \pm 0.007$ & $0.007 \pm 0.003$ & 9 & -9 & $1.033 \pm 0.001$ & $1.000 \pm 0.000$ & $0.99 \pm 0.000$ \\
\hline Shannon-Wiener & 1.070 & $1.719 \pm 0.182$ & $0.649 \pm 0.020$ & $1.000 \pm 0.000$ & $0.890 \pm 0.011$ & $0.818 \pm 0.013$ & 4 & -1 & $1.132 \pm 0.038$ & $1.554 \pm 0.296$ & $0.647 \pm 0.042$ \\
\hline Pielou equitability & 0.644 & $1.501 \pm 0.035$ & $0.857 \pm 0.007$ & $0.991 \pm 0.004$ & $0.949 \pm 0.008$ & $0.926 \pm 0.009$ & 8 & -2 & $1.053 \pm 0.010$ & $1.515 \pm 0.089$ & $0.825 \pm 0.016$ \\
\hline \multicolumn{12}{|c|}{ Preserved Cerrado } \\
\hline & $D_{-10}-D_{10}$ & $\mathrm{D}_{-10}$ & $\mathrm{D}_{10}$ & $\mathrm{D}_{0}$ & $\mathrm{D}_{1}$ & $\mathrm{D}_{2}$ & $q_{+}$ & q. & $\alpha_{0}$ & $\alpha_{\max }$ & $\alpha_{\min }$ \\
\hline Individuals.trap ${ }^{-1} \cdot$ day $^{-1}$ & 1.040 & $1.568 \pm 0.06$ & $0.528 \pm 0.067$ & $0.991 \pm 0.004$ & $0.860 \pm 0.025$ & $0.758 \pm 0.042$ & 2 & -2 & $1.136 \pm 0.041$ & $1.578 \pm 0.140$ & $0.668 \pm 0.110$ \\
\hline Richness & 0.113 & $1.057 \pm 0.021$ & $0.945 \pm 0.014$ & $0.991 \pm 0.004$ & $0.988 \pm 0.003$ & $0.986 \pm 0.003$ & 6 & -6 & $0.994 \pm 0.009$ & $1.082 \pm 0.062$ & $0.944 \pm 0.027$ \\
\hline Shannon-Wiener & 1.206 & $1.733 \pm 0.180$ & $0.527 \pm 0.056$ & $1.000 \pm 0.000$ & $0.868 \pm 0.019$ & $0.759 \pm 0.035$ & 2 & -1 & $1.146 \pm 0.045$ & $1.571 \pm 0.293$ & $0.662 \pm 0.096$ \\
\hline Pielou equitability & 0.233 & $1.144 \pm 0.035$ & $0.911 \pm 0.020$ & $1.000 \pm 0.000$ & $0.992 \pm 0.001$ & $0.984 \pm 0.003$ & 5 & -3 & $1.009 \pm 0.003$ & $1.110 \pm 0.059$ & $0.921 \pm 0.033$ \\
\hline \multicolumn{12}{|c|}{ Disturbed Cerrado } \\
\hline & $\mathrm{D}_{-10}-\mathrm{D}_{10}$ & $\mathrm{D}_{-10}$ & $\mathrm{D}_{10}$ & $D_{0}$ & $\mathrm{D}_{1}$ & $\mathrm{D}_{2}$ & $q_{+}$ & $q$ & $\alpha_{0}$ & $\alpha_{\max }$ & $\alpha_{\min }$ \\
\hline Individuals trap ${ }^{-1}$ day $^{-1}$ & 0.735 & $1.427 \pm 0.059$ & $0.692 \pm 0.038$ & $1.000 \pm 0.000$ & $0.916 \pm 0.014$ & $0.845 \pm 0.026$ & 3 & -2 & $1.087 \pm 0.028$ & $1.404 \pm 0.142$ & $0.717 \pm 0.081$ \\
\hline Richness & 0.393 & $1.309 \pm 0.050$ & $0.916 \pm 0.005$ & $0.981 \pm 0.011$ & $0.960 \pm 0.010$ & $0.947 \pm 0.009$ & 10 & -2 & $1.008 \pm 0.028$ & $1.241 \pm 0.099$ & $0.902 \pm 0.010$ \\
\hline Shannon-Wiener & 1.249 & $1.924 \pm 0.205$ & $0.675 \pm 0.029$ & $0.993 \pm 0.004$ & $0.879 \pm 0.017$ & $0.812 \pm 0.021$ & 4 & -0 & $1.145 \pm 0.044$ & $1.145 \pm 0.046$ & $0.674 \pm 0.057$ \\
\hline Pielou equitability & 0.361 & $1.262 \pm 0.057$ & $0.901 \pm 0.011$ & $0.981 \pm 0.011$ & $0.964 \pm 0.011$ & $0.951 \pm 0.011$ & 10 & -2 & $1.001 \pm 0.022$ & $1.173 \pm 0.077$ & $0.867 \pm 0.027$ \\
\hline \multicolumn{12}{|c|}{ Pasture } \\
\hline & $\mathrm{D}_{-10}-\mathrm{D}_{10}$ & $\mathrm{D}_{-10}$ & $\mathrm{D}_{10}$ & $D_{0}$ & $\mathrm{D}_{1}$ & $\mathrm{D}_{2}$ & $q_{+}$ & $q$ & $\alpha_{0}$ & $\alpha_{\max }$ & $\alpha_{\min }$ \\
\hline Individuals.trap ${ }^{-1} \cdot$ day $^{-1}$ & 0.638 & $1.370 \pm 0.080$ & $0.732 \pm 0.051$ & $0.999 \pm 0.001$ & $0.948 \pm 0.012$ & $0.897 \pm 0.024$ & 2 & -2 & $1.050 \pm 0.020$ & $1.311 \pm 0.160$ & $0.847 \pm 0.069$ \\
\hline Richness & 0.411 & $1.331 \pm 0.073$ & $0.920 \pm 0.010$ & $0.993 \pm 0.004$ & $0.975 \pm 0.006$ & $0.964 \pm 0.006$ & 8 & -1 & $1.018 \pm 0.006$ & $1.123 \pm 0.057$ & $0.895 \pm 0.028$ \\
\hline Shannon-Wiener & 0.895 & $1.582 \pm 0.133$ & $0.686 \pm 0.032$ & $0.995 \pm 0.003$ & $0.915 \pm 0.015$ & $0.848 \pm 0.022$ & 3 & -1 & $1.083 \pm 0.027$ & $1.352 \pm 0.164$ & $0.715 \pm 0.063$ \\
\hline Pielou equitability & 0.300 & $1.219 \pm 0.055$ & $0.919 \pm 0.020$ & $0.993 \pm 0.004$ & $0.980 \pm 0.006$ & $0.970 \pm 0.008$ & 6 & -2 & $1.010 \pm 0.004$ & $1.154 \pm 0.097$ & $0.912 \pm 0.041$ \\
\hline
\end{tabular}




\section{CONCLUSION}

Soil management influenced the biological diversity of the organisms in the studied areas, with higher Shannon diversity (2.69) and Pielou equability (0.84) values described for the treatment cultivated with soybean, where the taxonomic groups are evenly distributed throughout the transect, corresponding to a monofractal tendency.

The multifractality for the richness index evaluated by the singularity spectrum showed a well-defined structure with different degrees of asymmetry of branches and with the smaller heterogeneity of scale in the distribution of richness values.

\section{FUNDING}

Fundação de Amparo à Pesquisa e ao Desenvolvimento Científico e Tecnológico do Maranhão [https://doi.org/10.13039/501100003758]

Grant \# Process BM-01267/15, BEPP-01301/15, UNIVERSAL-00735/15 and BEST-EXT-00360/19

Coordenação de Aperfeiçoamento de Pessoal de Nível Superior - Brasil

[https://doi.org/10.13039/501100002322]

Grant \# Finance Code 001

Conselho Nacional de Desenvolvimento Científico e Tecnológico

[https://doi.org/10.13039/501100003593]

Grant \# Process 429354/2016-9, 307619/2016-8 and 103961/2018-6

\section{AUTHORS' CONTRIBUTION}

Conceptualization, Silva R. A. and Siqueira G. M.; Methodology, Silva R. A. and Siqueira G. M.; Investigation, Siqueira G. M.; Writing - Original Draft, Silva R. A. and Siqueira G. M.; Writing - Review and Editing, Silva R. A. and Siqueira G. M.; Funding Acquisition, Siqueira G. M.; Resources, Siqueira G. M.; Supervision, Siqueira G. M.

\section{REFERENCES}

[USDA] United States Department of agriculture (1999). United States Department of Agriculture - soil taxonomy: a basic system of soil classification for making and interpreting soil surveys. Washington: Agriculture Handbook.

Aquino, A. M. (2001). Manual para macrofauna do solo. Rio de Janeiro: Embrapa.

Banerjee, S., He, Y., Guo, X. and Si, B. C. (2011). Spatial relationships between leaf area index and topographic factors in a semiarid grassland Joint multifractal analysis. Australian Journal of Crop Science 6, 756-763.

Bardgett, R. D. and van der Putten, W. H. (2014). Belowground biodiversity and ecosystem functioning, Nature, 515, 505-511. https://doi:10.1038/nature13855

Chhabra, A. B. and Jensen, R. V. (1989). Direct determination of the $f(\alpha)$ singularity spectrum. Physical Review Letters, 62, 13271330. https://doi.org/10.1103/PhysRevLett.62.1327 
Dafonte, J. D., Valcárcel-Armesto, M., Silva Dias, R. and Paz-González, A. (2015). Assessment of the spatial variability of soil chemical properties along a transect using multifractal analysis. Cuadernos do Laboratorio Xeolóxico de Laxe, 38, 11-24.

Evertsz, C. J. G. and Mandelbrot, B. B. (1992). Multifractal measures. In H. Peitgen, H. Jürgens, and D. Saupe (Eds.), Chaos and Fractals (p. 921-953). Berlin: Springer.

García-Segura, D., Castillo-Murrieta, I. M., Martínez-Rabelo, F., Gomez-Anaya, A., Rodríguez-Campos, J., Hernández-Castellanos, B., Contreras-Ramos, S. M. and Barois, I. (2018). Macrofauna and mesofauna from soil contaminated by oil extraction. Geoderma, 332, 180-189. https://doi.org/10.1016/j.geoderma.2017.06.013

Gholami, A., Sheikhmohamadi, B. and Sayad, E. (2017). Spatial relationship between soil macrofauna biodiversity and trees in Zagros forests, Iran. Catena, 159, 1-8. https://doi.org/10.1016/j.catena.2017.07.021

Gouyet, J. F. (1996). Physics and Fractals Structure. Nova York: Springer.

Hentschel, H. G. E. and Procaccia, I. (1983). The infinite number of generalized dimensions of fractals and strange attractors. Physica D: Nonlinear Phenomena, 8, 435-444. https://doi.org/10.1016/0167-2789(83)90235-X

Korboulewsky, N., Perez, G. and Chauvat, M. (2016). How tree diversity affects soil fauna diversity: a review. Soil Biology. Biochemistry, 94, 94-106. https://doi.org/10.1016/j.soilbio.2015.11.024

Magurran, A. E. (2004). Measuring biological diversity. Oxford: Blackweel.

Mandelbrot, B. B. (1982). The Fractal Geometry of Nature. 2. ed. San Francisco: W. H. Freeman and Company.

Marichal, R., Grimaldi, M., Feijoo, A. M., Oszwald, J., Praxades, C., Cobo, D. H. R., Hurtado, M. P., Desjardins, T., Silva Junior, M. L. S., Costa, L. G., Miranda, I. S., Oliveira, M. N. D., Brown, G. G., Tsélouiko, S., Martins, M. B., Decaëns, T., Velasquez, E. and Lavelle, P. (2014). Soil macroinvertebrate communities and ecosystem services in deforested landscapes of Amazonia. Applied Soil Ecology, 83, 177-185. https://doi.org/10.1016/j.apsoil.2014.05.006

Martins, A. L. P., Siqueira, G. M., Moura, E. G., Silva, R. A., Silva, A. J. C. and Aguiar, A. C. F. (2018). Associations between different soil management practices soil fauna and maize yield. Journal of Agricultural Science, 10, 333-343. https://doi.org/10.5539/jas. v10n9p333

Mueller, K. E., Eisenhauer, N., Reich, P. B., Hobbie, S. E., Chadwick, O. A., Chorover, J., Dobies, T., Hale, C. M., Jagodzinski, A.M., Kalucka, I., Kasprowicz, M., Kieliszewska-Rokicka, B., Modrzynski, J., Rozen, A., Skorupski, M., Sobczyk, L., Paul, B. K., Vanlauwe, B., Hoogmoed, M., Hurisso, T. T., Ndabameye, T., Terano, Y., Six, J., Ayuke, F. O. and Pulleman, M. M. (2015). Exclusion of soil macrofauna did not affect soil quality but increased crop yields in a sub-humid tropical maize-based system. Agriculture, Ecosystems \& Environment, 208, 75-85. https://doi.org/10.1016/j.agee.2015.04.001

Paz-Ferreiro, J., Marinho, M. A., Abreu, C. A. and Vidal-Vázquez, E. (2018). Soil texture effects on multifractal behaviour of nitrogen adsorption and desorption isotherms. Biosystems Engineering. 168, 121-132. https://doi.org/10.1016/j.biosystemseng.2018.01.009

Silva, R. A., Aguiar, A. C. F., Rebêlo, J. M. M., França e Silva, Ê. F., Silva, G. F. and Siqueira, G. M. (2019). Diversity of edaphic fauna in different soil occupation systems. Revista Caatinga, 32, 647-657. https://doi.org/10.1590/1983-21252019v32n309rc

Silva, R. A., Siqueira, G. M., Costa, M. K. L., Guedes Filho, O. and Silva, Ê. F.F. (2018). Spatial variability of soil fauna under different land use and managements. Revista Brasileira de Ciência do Solo, 42, 1-18. https://doi.org/10.1590/18069657rbcs20170121

Siqueira, G. M., Silva, Ê. F. F., Vidal-Vazquéz, E. and Paz-González, A. (2018). Multifractal and joint multifractal analysis of general soil properties and altitude along a transect. Biosystems Engineering, 168, 105-120. https://doi.org/10.1016/j.biosystemseng.2017.08.024

Vidal-Vázquez, E., Camargo, O. A., Vieira, S.R., Miranda, J. G. V., Menk, J. R. F., Siqueira, G. M., Mirás-Avalos, J. M. and González, A. P. (2013). Multifractal analysis of soil properties along two perpendicular transects. Vadose Zone Journal, 12, 1-13. 
Wardle, D. A., Yeates, G, W., Barker, G. M. and Bonner, K. I. (2006). The influence of plant litter diversity on decomposer abundance and diversity. Soil biology and Biochemistry, 38, 1052-1062. https://doi.org/10.1016/j.soilbio.2005.09.003

Yakimov, B. N., Gelashvili, D. B., Zhang, Y., Markelov, I. N., Zhang, S. and Ma, K. (2018). Quantification of non-power-law diversity scaling with local multifractal Analysis. Ecological Informatics, 48, 48-59. https://doi.org/10.1016/j.ecoinf.2018.08.001

Yakimov, B. N., Solntsev, L. A., Rozenberg, G. S., Ludin, D. I., Shirokov, A. I., Lokteva, O. A. and Gelashvili, D. B. (2014). Local multifractal analysis of the spatial structure of Meadow comminities at small scale. Doklady Biological Sciences, 458, $297-301$. https://doi.org/10.1134/S0012496614050123. 